\title{
Heat shock protein responses to eccentric weight or treadmill exercise in active young females
}

Valiollah Dabidi-Roshan • Nader Rahnama · Hoda Abdi Hamzehkolaei · Zia Fallah Mohammadi

(C) Springer-Verlag 2010

Erratum to: Sport Sci Health

DOI: $10.1007 / \mathrm{s} 11332-009-0081-y$

Unfortunately the article contains erroneous data. Please

find the correct data here

\section{Results}

Page 78 Fig. 2. In the vertical line (U/L) CK should be replaced with $\mathrm{CK}(\mathrm{U} / \mathrm{L})$

Page 78 Fig 3. In the vertical line (Centigrad) Body temperature should be replaced with Body temperature (Centigrade).

\section{Discussions}

Page 78, line 13, Hsp70 should be replaced with HSP70

The online version of the original article can be found under doi: 10.1007/s11332-009-0081-y

V. Dabidi-Roshan $\cdot$ Z. Fallah Mohammadi

College of Physical Education and Sport Sciences

University of Mazandaran

Babolsar, Iran

N. Rahnama (西)

University of Isfahan

Isfahan, Iran

e-mail: rahnamanader@yahoo.com

H. Abdi Hamzehkolaei

Islamic Azad University of Gorgan, Iran 